\title{
A Species-Specific and spatially-Explicit Model for Estimating Vegetation Water Requirements in Desert Riparian Forest Zones
}

\author{
Guofu Yuan ${ }^{1}$ (D) Xuchao Zhu ${ }^{1,2} \cdot$ Xinzhai Tang $^{1} \cdot$ \\ Tao Du ${ }^{1,2} \cdot$ Xiaobo $\mathrm{Yi}^{3}$
}

Received: 17 March 2016 / Accepted: 6 June 2016/

Published online: 11 June 2016

(C) Springer Science+Business Media Dordrecht 2016

\begin{abstract}
Balancing human demands for water with environmental requirements to maintain functioning ecosystems requires the quantification of ecological water requirements. In arid regions, high spatial variability of vegetation cover and different water consumption of plant species make it different to estimate reasonable ecological water requirements. We developed a simple and practical approach that estimates the vegetation water requirements (VWRs) of desert riparian ecosystems. This model is species-specific and spatially-explicit; it considers the water consumption characteristics required by different species and highlights the impacts that high vegetation cover spatial variability has in arid regions on evapotranspiration. The model was parameterized based on the observation of the water consumption of two typical desert riparian species, Populus euphratica and Tamarix spp., in the lower basin of the Tarim River in northwestern China. Comparisons between the modeling results and measured data for two mature Populus and Tamarix stands indicate that the model is reasonable predictive. A case study in the lower basin of the Tarim River demonstrated the model's practicality and transferability. This model could run based on near real-time or forest weather data and spatial vegetation patterns, and provides a continuous estimation of the temporal and spatial variations of the VWR. Particularly, this model forecasts VWRs under different vegetation spatial distribution and coverage scenarios, and evaluates the impacts and consequences of different management actions. This model can serve as a useful tool for management agencies interested in improving their decisions to allocate river water between human activities and natural ecosystems in arid regions.
\end{abstract}

\section{Guofu Yuan}

yuangf@igsnrr.ac.cn

1 Key Laboratory of Ecosystem Network Observation and Modeling, Institute of Geographic Sciences and Natural Resources Research, Chinese Academy of Sciences, Beijing 100101, China

2 University of Chinese Academy of Sciences, Beijing 100049, China

3 College of Natural Resources and Environment, Northwest A \& F University, Yangling 712100, China 
Keywords Vegetation water requirement - Desert riparian forest - Arid region - Tamarix spp. Populus euphratica $\cdot$ Endorheic river

\section{Introduction}

In arid northwestern China and central Asia, there are many endorheic rivers, which usually originate from high mountain glaciers, and rush from the mountains to cultivate oases in alluvial plains before crossing deserts or gobis, finally forming a terminal lake or disappearing in a great desert (Zheng and Yin 2010). In the lower reaches of these rivers, narrow desert riparian forest zones are often formed along the river banks. The riparian ecosystems fostered by these endorheic rivers are often vital to the control of desertification and ecosystem restoration in these areas. However, desert riparian ecosystems along endorheic rivers are highly vulnerable to sudden changes in river water supply and threats from frequent wind and sand erosion (Rumbaur et al. 2015). As human activities such as irrigation farming in the oases along the middle reaches of these rivers becomes increasingly intense, the water supply to the lower reaches has decreased and in some cases has dried up altogether (Feng and Cheng 1998). Reduced stream flow has given rise to obvious damage in these lower reaches riparian ecosystems (Chen 2003; Feng et al. 2005). In recent years, water diversion projects have occurred on the longest endorheic rivers in China, the Tarim River (Tao et al. 2008; Xu et al. 2007) and the Heihe River (Zhang et al. 2011), necessitating river and ecosystem restoration in the lower reaches. One of the primary goals of these projects was to supply water to the lower reaches in a planned way; however, water shortages in the middle-reach oases, where most people in arid regions live, challenge this goal. Balancing human demands for water with environmental requirements to maintain functioning ecosystems is crucial to the development of successful water resources management options for rivers in arid regions (Merritt and Bateman 2012). To efficiently and sustainably manage river water resources, it is important and necessary to reasonably estimate the ecological or environmental water requirements along these rivers in these arid regions (Rumbaur et al. 2015; Wang et al. 2012).

Basic ecological water requirements (EWR) are often defined as the minimum amount of water necessary to meet the basic needs of natural ecosystems (Gleick 1998). Generally, ecosystem evapotranspiration (ET) under non-water-stressed conditions is regarded as the essential measurement of a vegetated ecosystem's water requirements ( $\mathrm{Hu}$ et al. 2009; Liu et al. 2010). Thus an EWR estimate is also an estimate of ecosystem ET under non-waterstressed conditions. Methods to estimate ET differ widely, from simple empirical models based on pan evaporation or potential evaporation (Izadifar and Elshorbagy 2010; Sumner and Jacobs 2005), to comprehensive methods using process-based simulations (Daly et al. 2004; Sellers et al. 1997; Wang 2008). Different types of models, including ecological models, hydrological models and land surface models, can also simulate and calculate surface ET. Of the different methods used to estimate ET, physically-based methods are thought to have advantages over empirical approaches (Fernandes et al. 2007). However, most physicallybased models generally require complicated input data and parameters that focus on the interactions between different land surface processes; and these models are often developed to explore processes' controlling mechanisms without considering their feasibility and applicability in practical managements situations (Wang and Dickinson 2012).

The ultimate aim of developing an EWR estimation model is to improve sustainable water resources and ecosystems management; and management agencies often prefer simple, efficient 
estimation methods. A simple and practical method for estimating EWR should employ fewer variables and parameters while producing reasonable EWR estimation results. To address the regulation of water resource allocations in river reaches, a simple EWR estimation method should be able to predict temporal and spatial variations in EWR and evaluate those variations to forecast the impacts and consequences of different management options and projects on water availability. In recent years, many weather networks have provided reference ET figures to estimate agricultural crop water requirements, following FAO56 methods (Allen et al. 1998). Methods to estimate the EWR of natural ecosystems derived from the FAO56 method have also been developed for near real-time and forecast management (Irmak et al. 2013; Spano et al. 2009). However, these methods cannot be directly applied in desert and arid riparian ecosystems because of the highly spatial variability of desert riparian vegetation cover. In FAO56 method, the crop coefficients, $K_{\mathrm{c}}$, usually simplify the impacts of vegetation cover spatial variability. In hyper-arid regions, surface ET is almost entirely the result of plant transpiration (Yuan et al. 2014). This phenomenon indicates that regional ET amount in hyper-arid regions is largely controlled by vegetation cover (Yuan et al. 2015). Given the high spatial variability of vegetation cover in arid environments ( $\mathrm{Li}$ et al. 2013; Xu et al. 2007), it is necessary to develop simple ET model to consider the effect of variable vegetation cover in hyper-arid regions.

Methods to estimate the EWR of desert riparian ecosystems in different endorheic rivers of China have been developed previously (Ling et al. 2014; Liu et al. 2010; Ye et al. 2010; Zhao et al. 2007). However, these methods generated approximate results that did not consider the unique characteristics of surface ET processes in desert riparian communities, and the models were not calibrated or validated. Consequently, the estimates provided by these models do not meet the needs of endorheic river water resources and ecosystems management teams. Furthermore, because these methods generally were not developed based on real-time weather data or spatial vegetation patterns, they do not provide temporally or spatially variable EWR figures. Considering the difference in water requirements between species and the spatial change of vegetation cover in an EWR estimation model can improve the model's accuracy, which is important for water resources and ecosystem management of endorheic rivers in arid regions and can lead to EWR forecasts under different spatial distributions and plant species coverage scenarios, as well as the evaluation of the impacts and consequences of different management actions.

In this paper, we relied on our understanding of the surface ET processes through a four-year observation of desert riparian forests in the lower reach of the Tarim River of China (Yuan et al. 2015; Yuan et al. 2014) to develop a simple, practical model to estimate riparian forest water requirements in the lower reaches of the endorheic rivers in arid regions. The model can run on near real-time or forecast weather data and, thus, can provide a continuous estimation of vegetation water requirements. It is a species-specific and spatially-explicit model, and it highlights different species' water requirements and the impacts of spatial changes in vegetation cover on those requirements. This model can serve as a valuable tool for water resources and ecosystems management agencies in arid regions because it is a practical and transferable way to estimate EWR.

\section{Model Description}

\subsection{Definition, Assumptions and Model Descriptions}

In this study, the essential water requirements of desert riparian forests are defined as the regional ET of desert riparian forests without water stress, in other words, the regional 
maximum ET $\left(\mathrm{ET}_{\mathrm{m}}\right)$ under local climate and actual vegetation cover conditions. This definition represents vegetation water requirements (VWR) rather than total ecological or environmental water requirements (EWR). EWR includes different all water requirements necessary for the maintenance of an ecosystem, including water for vegetation, the river channel, and a terminal lake (Acreman et al. 2014; Meijer et al. 2012). EWR estimates are important to water resources management agencies; However, VWR is an important foundation for the estimation of EWR and so is the focus of this paper.

Due to scarce precipitation, desert riparian forests in arid regions are often typical terrestrial groundwater-dependent ecosystems (Bertrand et al. 2012; Orellana et al. 2012). Soil evaporation is often very weak due to nearly completely dry soil surfaces; as a result, its contribution to surface ET is miniscule (Yuan et al. 2014). According to a three-year observation of surface ET over desert riparian forests in the lower Tarim River basin of China, the spatial pattern of surface ET is mainly controlled by the vegetation leaf area index (LAI), and seasonal ET is controlled by plant phenology in the hyper-arid climate (Yuan et al. 2015). In the lower reaches of endorheic rivers in China, vegetation coverage is often highly spatially variable, which results in significant spatial variations in surface ET. Therefore, a modified crop coefficient approach highlighting the spatial changes of regional $\mathrm{ET}_{\mathrm{m}}$ was drawn from the FAO56 method and employed to develop an empirical model that estimates desert riparian forest VWR.

In the model presented here, the VWR of desert riparian forests without water stress, or the $\mathrm{ET}_{\mathrm{m}}$, is determined by atmospheric and biotic factors. The model was developed to estimate the spatial and temporal patterns in daily $\mathrm{ET}_{\mathrm{m}}$ over desert riparian forests:

$$
\mathrm{ET}_{\mathrm{m}}=f(\text { structural }) \cdot f(\text { physiological }) \cdot \mathrm{ET}_{0}
$$

where, $\mathrm{ET}_{0}$ is the reference $\mathrm{ET}, f$ (physiological) is a function of vegetation physiological activities, and $f$ (structural) is a function of vegetation structural characteristics and dynamics, which highlights the role of vegetation coverage in regional ET.

$\mathrm{ET}_{0}$ is the daily reference ET $\left(\mathrm{mm} \mathrm{d}^{-1}\right)$ described using the FAO56 method. It can be calculated by the FAO56 Penman-Monteith equation based on weather data (Allen et al. 1998):

$$
\mathrm{ET}_{0}=\frac{0.408 \Delta\left(R_{\mathrm{n}}-G\right)+\gamma \frac{900}{T+273} u_{2} D}{\Delta+\gamma\left(1+0.34 u_{2}\right)}
$$

where, $R_{\mathrm{n}}$ is net radiation $\left(\mathrm{MJ} \mathrm{m}^{-2} \mathrm{~d}^{-1}\right), G$ is the soil heat flux density $\left(\mathrm{MJ} \mathrm{m}^{-2} \mathrm{~d}^{-1}\right), T$ is the mean daily air temperature $\left({ }^{\circ} \mathrm{C}\right), u_{2}$ is the wind speed at $2 \mathrm{~m}$ height $\left(\mathrm{m} \mathrm{s}^{-1}\right), D$ is the saturation vapor pressure $(\mathrm{kPa}), \Delta$ is the slope vapor pressure curve $\left(\mathrm{kPa}^{\circ} \mathrm{C}^{-1}\right)$, and $\gamma$ is a psychrometric constant $\left(\mathrm{kPa}^{\circ} \mathrm{C}^{-1}\right)$.

Because LAI determines the spatial pattern of desert riparian forest ET (Yuan et al. 2014), the function of the vegetation's structural characteristics and dynamics, $f$ (structural), can be described as:

$$
f(\text { structural })=\alpha_{\mathrm{p}} \cdot \mathrm{LAI}
$$

where, LAI is the leaf area index, and $\alpha_{\mathrm{p}}$ is a species-specific parameter describing the impact of the structural traits of specific species on $\mathrm{ET}_{\mathrm{m}}$. In a desert riparian forest community along a low reach of an endorheic river in China, there is often one dominant species, and species richness is usually low (Tao et al. 2008; Zhu et al. 2012). Therefore, the parameter $\alpha_{\mathrm{p}}$ can also be seen as a community-specific parameter. 
In this model, a simple linear relationship is used to describe the impact of plant physiological activities on daily ET (Spano et al. 2009):

$$
f(\text { physiological })=K_{\mathrm{b}}
$$

where, $K_{\mathrm{b}}$ is a species-specific parameter expressing the impact of species physiological activities on $\mathrm{ET}_{\mathrm{m}}$ under non-water stress conditions. Combining Eqs. (1), (2) and (3), a simple equation to calculate the VWR of desert riparian forests in arid regions, namely, daily $\mathrm{ET}_{\mathrm{m}}$ can be written as:

$$
\mathrm{ET}_{\mathrm{m}}=\alpha_{\mathrm{p}} \cdot \mathrm{LAI} \cdot K_{\mathrm{b}} \cdot \mathrm{ET}_{0}
$$

In this model, parameters $\alpha_{\mathrm{p}}$ and $K_{\mathrm{b}}$ represent the effects of different plant species on $\mathrm{ET}_{\mathrm{m}}$, LAI reflects the spatial changes of VWR, and $\mathrm{ET}_{0}$ expresses the effects of atmospheric factors on $\mathrm{ET}_{\mathrm{m}}$. LAI should be seasonally variable, and $\alpha_{\mathrm{p}}$ and $K_{\mathrm{b}}$ should be parameterized for different plant phenological stages. After obtaining the parameters $\alpha_{\mathrm{p}}$ and $K_{\mathrm{b}}$ for all types of plant species in a given region, the regional VWR of desert riparian forests and their temporal and spatial patterns can be obtained easily and quickly based on remotely sensed regional LAI and observed weather data.

\subsection{Parameterization Method of Model}

\subsubsection{Seasonal Variation of LAI Values}

A process to determine the seasonal LAI must be developed in this model because the direct measurement of LAI is laborious. Actually, for desert riparian forests with low species richness, seasonal change in the LAI can be simplified into a trapezoid process (Foley et al. 1996). The growing season of desert riparian forests can generally be divided into three phenological stages: the greening period (GP), the maturity period (MP), which includes the vegetative, blooming and fruit ripening phases; and the senescence period (SP). For each phenological stage, the change in LAI can be simplified. In GP, the LAI value increases linearly from 0 to the maximum LAI $\left(\mathrm{LAI}_{\mathrm{m}}\right)$. In MP, the LAI does not vary, remaining at $\mathrm{LAI}_{\mathrm{m}}$. In SP, the LAI value decreases linearly from $\mathrm{LAI}_{\mathrm{m}}$ to 0 . During the non-growing season, the LAI is 0 . By simplifying seasonal changes in LAI, an LAI value can be obtained for each day based on LAI $_{\mathrm{m}}$ and the plant's phenological date. For a single observation plot, $\mathrm{LAI}_{\mathrm{m}}$ can be measured in MP. For an entire region, remotely sensed data can be used to obtain the spatial pattern of $\mathrm{LAI}_{\mathrm{m}}$. Regional plant phenological dates can be determined from phenology observation data.

\subsection{2 $\alpha_{p}$ and $K_{b}$ Values}

Determining the values of $\alpha_{\mathrm{p}}$ and $K_{\mathrm{b}}$ separately in the model is unnecessary as water requirements can be calculated by obtaining the product of $\alpha_{\mathrm{p}}$ and $K_{\mathrm{b}}$. The value of $\alpha_{\mathrm{p}} \cdot K_{\mathrm{b}}$ can be obtained by converting the Eq. (5) as follows:

$$
\alpha_{\mathrm{p}} \cdot K_{\mathrm{b}}=\frac{\mathrm{ET}_{\mathrm{m}} / \mathrm{ET}_{0}}{\mathrm{LAI}}
$$

By fitting measured $\mathrm{ET}_{\mathrm{m}} / \mathrm{ET}_{0}$ and LAI linearly for the three different phenological stages, $\alpha_{\mathrm{p}} \cdot K_{\mathrm{b}}$ for GP, MP and SP can be obtained. 
Equation (6) suggests that, in this model, the relationship between surface ET without water stress and $\mathrm{ET}_{0}$ should be linearly significant during the MP because the LAI remains unchanged; and the ratio of $\mathrm{ET}_{\mathrm{m}}$ to $\mathrm{ET}_{0}$ should be related linearly to the LAI during the GP and SP periods. The effectiveness of fitting the data between measured $\mathrm{ET}_{\mathrm{m}} / \mathrm{ET}_{0}$ and $\mathrm{LAI}$ can also verify the feasibility of the model presented here.

\section{Materials and Methods}

Field observations were conducted to parameterize and test the model. A case study in the lower Tarim River basin of China was executed to evaluate the practicality of the model for water resources management agencies.

\subsection{Site Descriptions}

The lower reach of the Tarim River was chosen for field observations. The Tarim River is the longest endorheic river in China. The lower reach of the Tarim River is located between the Taklimagan Desert and the Kuluk Desert and runs from the Daxihaizi reservoir to the terminal Taitmar Lake. The lower river is approximately $300 \mathrm{~km}$ long (Fig. 1). The Tarim basin is a relatively flat desert region with a mean annual precipitation of less than $50 \mathrm{~mm}$ and an annual potential evaporation as high as $2000 \mathrm{~mm}$. Under this hyper-arid desert climate, desert riparian vegetation dominates. The narrow riparian forest zone in the lower reach of the Tarim River

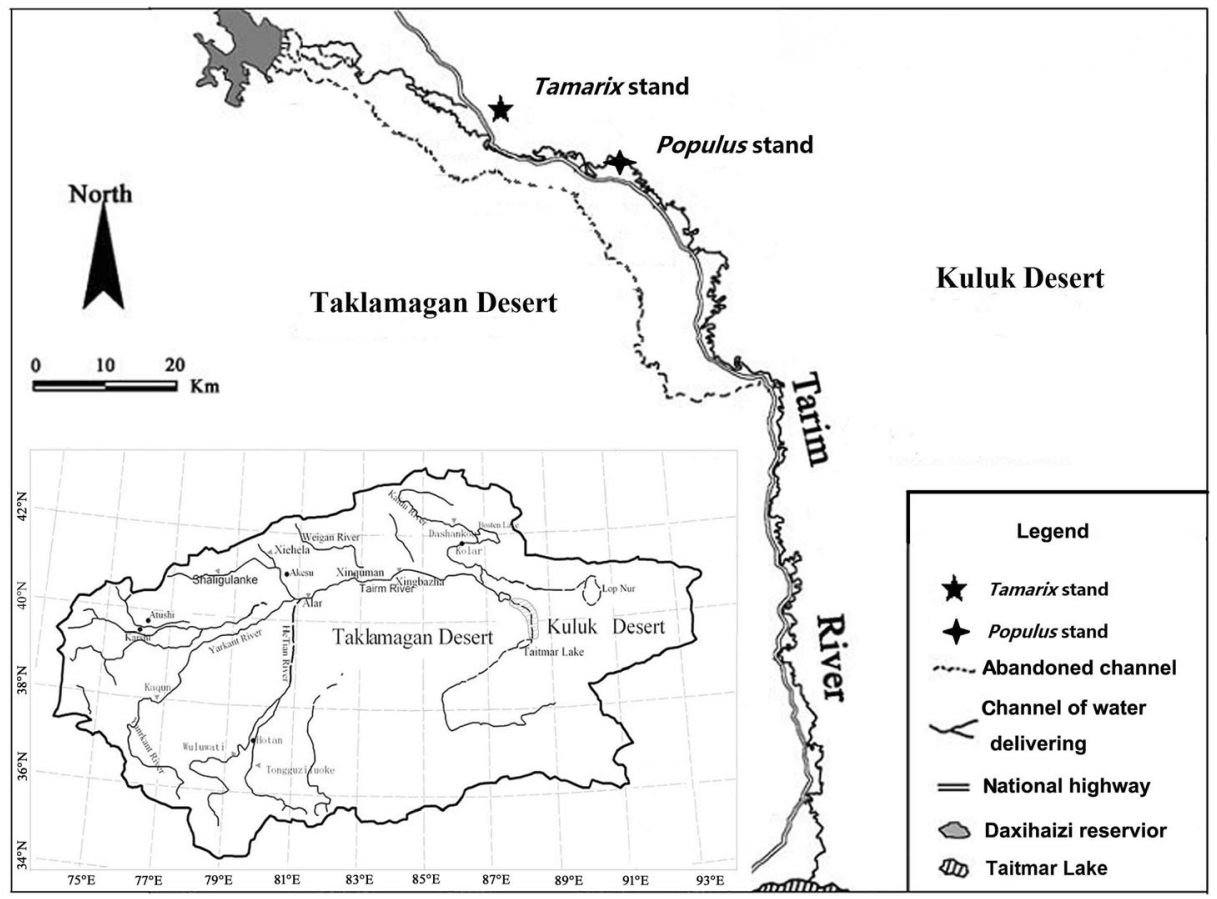

Fig. 1 Locations of the case study area, the lower basin of the Tarim River in China 
has a width of approximately $3 \mathrm{~km}$ or less and forms a "green corridor" that protects the ancient silk road and a current national road along the river.

The plant communities in this area are generally classified into two categories: Populus (Populus euphratica) woodland and Tamarix (Tamarix spp.) thicket. The Populus woodland belongs to the arboreal forest ecosystem and the Tamarix thicket belongs to the shrub ecosystem. Species richness in these plant communities is low. A small number of other shrubs and herbs, such as Lycium ruthenicum, Halimodendron halodendron, Phragmites australis, Apocynum venetum, Alhagi sparsifolia, Karelinia caspica, Glycyrrhiza inflata, grow in the two communities. The coverage of plant communities in this area is also low due to scarce precipitation. The highest observed vegetation coverage was 0.65 in the riparian forests. Vegetation coverage in most of the region is less than 0.2 , and the spatial change between these densities is obvious.

Two typical, mature riparian vegetation stands were chosen to measure surface ET using the eddy covariance (EC) method. One stand was dominated by Populus euphratica and the other by Tamarix spp. According to our analysis, the two mature riparian vegetation communities were not under water stress (Yuan et al. 2015). Thus, measured surface ET over the two riparian stands can be regarded as the maximum ET under non-water-stressed conditions and can be used to parameterize the model and evaluate its performance.

The Tamarix stand chosen for observation covers an area of approximately $300 \mathrm{~m} \times 300 \mathrm{~m}$. This area is flat and is located at $87^{\circ} 54^{\prime} \mathrm{E}, 40^{\circ} 27^{\prime} \mathrm{N}$, with the altitude $846 \mathrm{~m}$. The vegetation coverage index was 0.65 . The average vegetation height was approximately $2 \mathrm{~m}$ and the leaf area index $\left(\mathrm{LAI}_{\mathrm{m}}\right)$, which was measured using an LAI-2250 canopy analyzer (Li-cor, Nebraska USA) during the MP, was 1.15. The dominant species in the stand are Tamarix ramosissima, Tamarix hispida and Tamarix elongat. A small number of herbs (mainly Alhagi sparsifolia and Glycyrrhiza infata) grow under the shrubs. The Simpson diversity index for the stand was 0.71 . The groundwater depth fluctuates between $5.6 \mathrm{~m}$ and $6.4 \mathrm{~m}$, and the soil is a silt loam with an approximately $20 \mathrm{~cm}$ dry sand surface layer.

The Populus stand chosen for observation is located at $88^{\circ} 1$ ' E, $40^{\circ} 26^{\prime} \mathrm{N}$, with an altitude of $844 \mathrm{~m}$. The stand covers an area of approximately $1.5 \mathrm{~km} \times 2 \mathrm{~km}$. The average vegetation height was approximately $10 \mathrm{~m}$, coverage was 0.47 and the leaf area index $\left(\mathrm{LAI}_{\mathrm{m}}\right)$ during the MP was 0.57. Excluding individual reeds spread along the river bank, Populus euphratica was the only species observed in the stand. The soil texture in the root layer is slightly complex, and the soil is a silt loam at a depth of 0 to $3 \mathrm{~m}$, while the soil is sandy below $3 \mathrm{~m}$. The groundwater depth fluctuates approximately $3.8 \mathrm{~m}$.

\subsection{ET Measurements and Data Processing}

Two flux towers were established to measure surface ET and other relevant factors over the two riparian forest stands, respectively. The EC technique was used to measure the energy and $\mathrm{CO}_{2} / \mathrm{H}_{2} \mathrm{O}$ fluxes on a continuous basis. Matching EC systems were installed on the flux towers in the Tamarix stand and the Populus stand, respectively. The Tamarix stand system was installed at a height of $1.8 \mathrm{~m}$ above the Tamarix canopy, and the Populus stand system was installed at a height of $5 \mathrm{~m}$ above the Populus canopy. Continuous measurements over the Tamarix stand were taken from June 8th, 2011, and continuous measurements over the Populus stand were taken from June 18th, 2013.

Surface evapotranspiration was obtained from the flux data sets. Detailed data processing for the EC data was introduced in our other articles (Yuan et al. 2015; Yuan et al. 2014). 


\subsection{Other Data}

Meteorological data were collected from the Tikanlik Weather Station (WMO number 51,765), a national weather observation stations in China located in the lower reach of the Tarim River. The station's distance from the two observation sites is approximately $30-40 \mathrm{~km}$. The meteorological data were used primarily to calculate daily $\mathrm{ET}_{0}$.

The leaf area indices over the Tamarix stand and the Populus stand were measured using a LI-2250 canopy analyzer (Li-cor, Nebraska USA) in July 2013. These values represent the $\mathrm{LAI}_{\mathrm{m}}$ values for the observation stands.

The phenology of desert riparian forests was divided into three stages: GP, MP and SP. The start and end dates for the three stages within Tamarix thickets and Populus woodlands in the lower Tarim River basin were determined from previous observational results (Abdurahman et al. 2008; Bai 1998). For Tamarix thickets, the GP runs from April 27 to June 3, the MP from June 4 to September 17, and the SP from September 18 to October 18. For Populus woodlands, the GP runs from March 29 to June 4, the MP from June 5 to September 25, and the SP from September 26 to November 12 .

\subsection{Model Evaluation Method}

We obtained the $\alpha_{\mathrm{p}} \cdot K_{\mathrm{b}}$ value for a Tamarix thicket using the data observed during the 2012 growing season and the $\alpha_{\mathrm{p}} \bullet K_{\mathrm{b}}$ value for a Populus woodland using data observed during the 2013 MP and SP stages and the 2015 GP stage. We compared model predictions with measured ET over the observed Tamarix stand from the 2011 and 2013 growing seasons and measured ET over the observed Populus stand from the 2014 growing season. The comparisons were assessed using the root mean square deviation (RMSD). The RMSE is computed as

$$
\mathrm{RMSD}=\left[\frac{1}{n} \sum_{i=1}^{n}\left(\mathrm{ET}_{\mathrm{m} i}-\mathrm{ET}_{i}\right)^{2}\right]^{1 / 2}
$$

Where, $\mathrm{ET}_{i}$ is the measured $\mathrm{ET}\left(\mathrm{mm} \mathrm{d}^{-1}\right)$ over the desert riparian forests during day $i$, and $\mathrm{ET}_{\mathrm{m} i}$ is the predicted ET under non-water stress conditions ( $\mathrm{mm} \mathrm{d}^{-1}$ ) as defined by Eq. (5).

In addition to RMSD, the Nash-Sutcliffe model efficiency coefficient (NSE) was used to assess the predictive power of the Eq. (5) approach in estimating the water requirements of different species:

$$
N S E=1-\frac{\sum_{i=1}^{n}\left(\mathrm{ET}_{i}-\mathrm{ET}_{\mathrm{m} i}\right)^{2}}{\sum_{i=1}^{n}\left(\mathrm{ET}_{i}-\mathrm{ET}_{i}\right)^{2}}
$$

The NSE values can range from $-\infty$ to 1 , where an efficiency of $1(N S E=1)$ indicates a perfect match of the modeled $\mathrm{ET}_{\mathrm{m}}$ to the observed ET. An efficiency of $0(N S E=0)$ indicates that the model predictions are as accurate as the mean of the observed data, whereas a negative efficiency $(N S E<0)$ occurs when the observed mean is a better predictor than the model or when the residual variance (numerator) is larger than the data variance (denominator). 


\section{Model Verification}

\subsection{Parameter $\alpha_{\mathrm{p}} \cdot K_{\mathrm{b}}$ Values}

In GP and LP of both the Tamarix thicket and the Populus woodland, the linear relationships between LAI and the ratio of daily ET to daily $\mathrm{ET}_{0}$ were significant. The correlation coefficients, $R^{2}$, ranged between 0.65 and 0.84 (Fig. 2). These significant linear relationships verified the rationality of the Eq. (5) in the GP and LP of plants. Based on this, the $\alpha_{\mathrm{p}} \bullet K_{\mathrm{b}}$ values during the GP and LP of both the Tamarix thicket and the Populus woodland could be obtained using the Eq. (6) (Table 1).

During the MP, the LAI values were not supposed to change with time. According to Eq. (5), the linear relationships between ET and $\mathrm{ET}_{0}$ should be significant during the MP for desert riparian vegetation. Figure 3 shows the relationships between ET and $\mathrm{ET}_{0}$ at hourly and daily scales. The linear relationships at the hourly scale were significant for both the Tamarix thicket and the Populus woodland (Fig. 3a, c); however, they were not significant between daily ET and daily $\mathrm{ET}_{0}$ (Fig. 3b, d). The poor correlations between daily ET and daily $\mathrm{ET}_{0}$ may be due to the narrow fluctuation ranges of daily ET during the MP. Although the correlations between daily ET and daily $\mathrm{ET}_{0}$ were poor, the $\alpha_{\mathrm{p}} \cdot K_{\mathrm{b}}$ values obtained during the MP based on the relationships between daily ET and daily $\mathrm{ET}_{0}$ using Eq. (6) were nearly equal to those for hourly ET and hourly $\mathrm{ET}_{0}$ (Fig. 3). Here, we used the fitted slope values of the daily ET and $\mathrm{ET}_{0}$ relationships to calculate the $\alpha_{\mathrm{p}} \bullet K_{\mathrm{b}}$ values for the MP based on Eq. (6). Table 1 lists the $\alpha_{\mathrm{p}}$ $-K_{\mathrm{b}}$ values that can be used in the model for different phenological stages of Tamarix thickets and Populus woodlands.
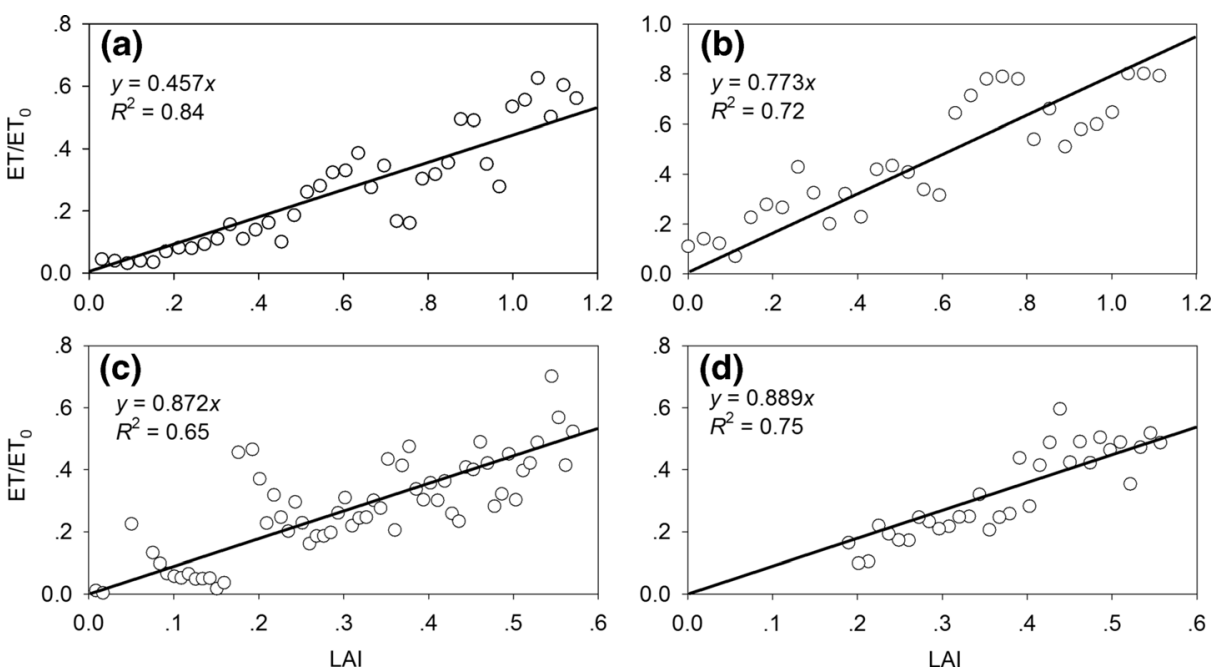

Fig. 2 Linear relationships between leaf area index (LAI) and the ratio of surface evapotranspiration (ET) versus corresponding reference evapotranspiration $\left(\mathrm{ET}_{0}\right)$ in $(\mathbf{a})$ greening period and (b) senescence period of the observed Tamarix stand, and in (c) greening period and (d) senescence period of the observed Populus stand. $P<0.0001$ 
Table 1 Values of $\alpha_{\mathrm{p}} K_{\mathrm{b}}$ suitable for use in the model at different phenological stages of Tamarix thickets and Populus woodlands

\begin{tabular}{lll}
\hline Phenological stages & Tamarix thickets & Populus woodlands \\
\hline GP & 0.457 & 0.872 \\
MP & 0.635 & 0.964 \\
SP & 0.773 & 0.889 \\
\hline
\end{tabular}

\subsection{Model Test}

The comparisons between the modeled $\mathrm{ET}_{\mathrm{m}}$ and the measured ET for the non-water-stressed Tamarix and Populus stands are shown in Fig. 4. Gaps in the measured ET data occurred because of a malfunctioning instrument. Nevertheless, the results indicate that seasonal variations and daily fluctuations in ET over the non-water-stressed Tamarix and Populus stands could be reproduced using Eq. (5). NSE values were $0.79,0.78$ and 0.59 for the 2011 and 2013 Tamarix growing seasons (Fig. 4 a, b) and the 2014 Populus growing season (Fig. 4 c), respectively, indicating that the modeled $\mathrm{ET}_{\mathrm{m}}$ values were close to the observed $\mathrm{ET}$ values. The corresponding RMSD values were $0.74,0.68$ and $0.63 \mathrm{~mm} \mathrm{~d}^{-1}$, indicating that the agreements of the trends between the modeled $\mathrm{ET}_{\mathrm{m}}$ and the observed ET were good.

A small number of large, intermittent differences between the modeled $\mathrm{ET}_{\mathrm{m}}$ and the observed ET were found. Particularly from June 20th to 22th, 2011 (Fig. 4 a), the mean ET was $5.09 \mathrm{~mm}$, but the mean $\mathrm{ET}_{\mathrm{m}}$ was $3.48 \mathrm{~mm}$. Two rare heavy precipitation events preceded those days, one on June 16th $(20.8 \mathrm{~mm})$ and one on June 19th $(15.7 \mathrm{~mm})$, which resulted in increased soil evaporation in the hyper-arid region. The additional contribution of soil evaporation after heavy precipitation could increase the total surface ET over desert riparian forests
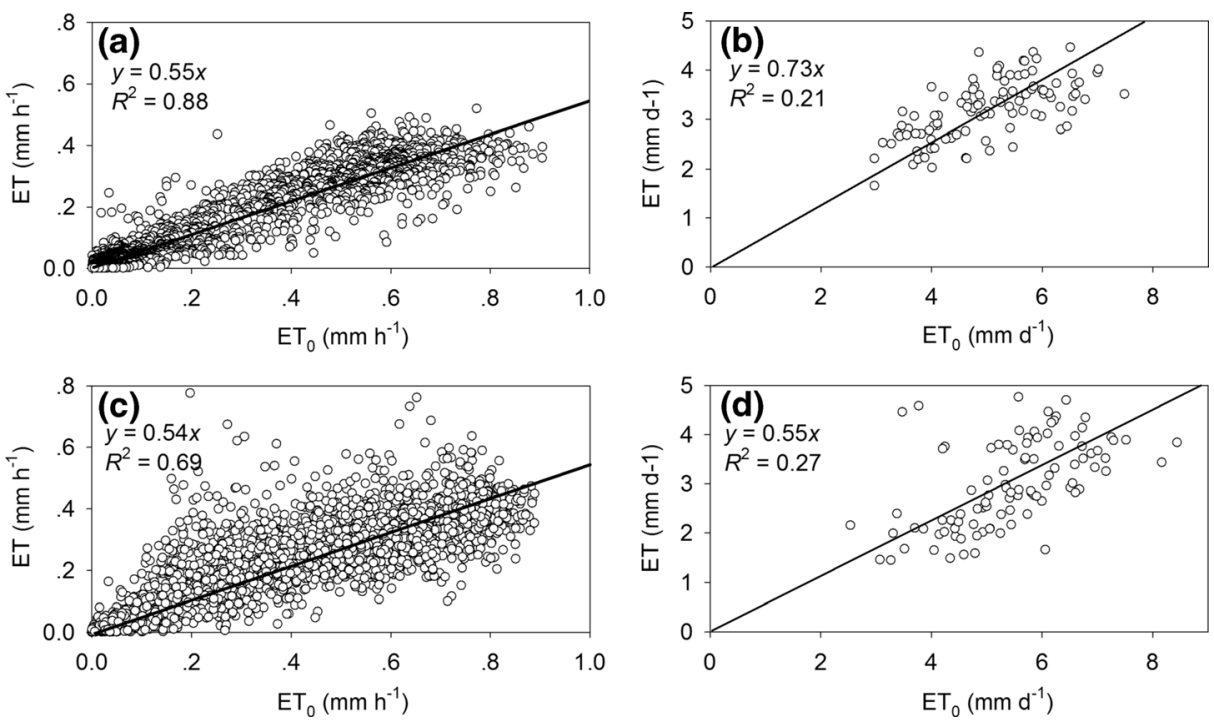

Fig. 3 Linear relationships between evapotranspiration (ET) and corresponding reference evapotranspiration $\left(\mathrm{ET}_{0}\right)$ in mature period of the observed Tamarix stand (a and b) and the observed Populus stand (c and d). Units are hourly in a and $\mathrm{c}$ and daily in $\mathrm{b}$ and $\mathrm{d} . P<0.0001$ 


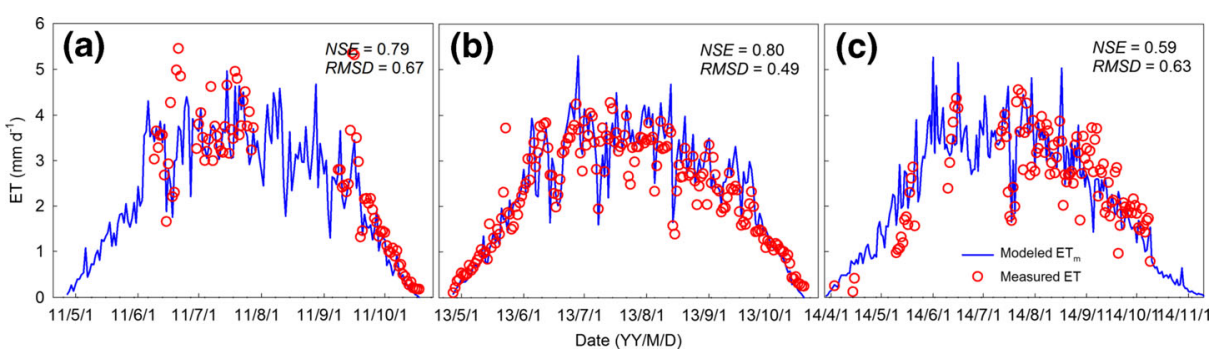

Fig. 4 Comparisons between the modeled maximum evapotranspiration $\left(\mathrm{ET}_{\mathrm{m}}\right)$ and the measured evapotranpiration (ET, Marked by red O) in (a) 2011 growing season of the Tamarix stand, (b) 2013 growing season of the Tamarix stand and (c) 2014 growing season of the Populus stand

under similar weather conditions. This result indicates that the model parameters may only be suitable for arid environment with little precipitation.

\section{Model Application: a Case Study in the Lower Tarim River Basin}

\subsection{Data Processing}

\subsubsection{Calculation Process}

The above model can provide continuous, near real-time estimations of the spatial and temporal variations of VWR based on three types of input data: satellite remote sensing data, meteorological data and vegetation phenological data (Fig. 5). Satellite remote sensing data provides the spatial distribution of different vegetation types and the inverse of their spatial $\mathrm{LAI}_{\mathrm{m}}$ values. Because this model is a species-specific model, different species or communication types must be spatially discerned by remote sensing methods; therefore, high spatial resolution remote sensing data are necessary for the model's application. At the catchment scale, Landsat TM data with

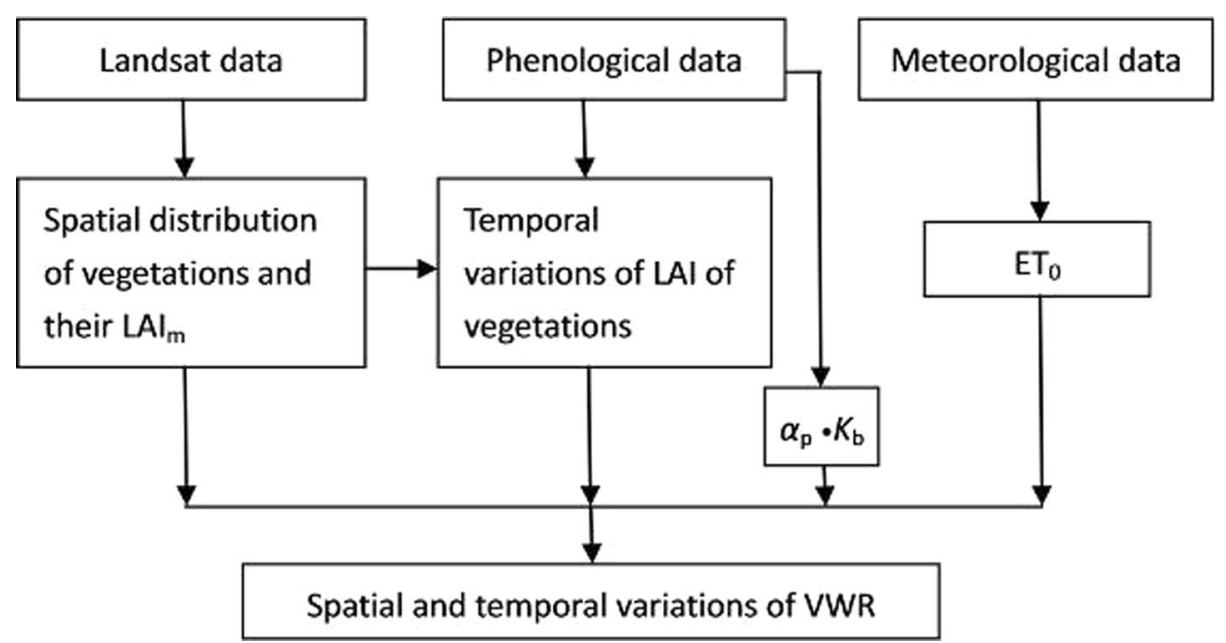

Fig. 5 Data preparation and calculation process of the model 
$30 \mathrm{~m} \times 30 \mathrm{~m}$ resolution are appropriate. Phenological data are used to estimate daily LAI processes for different vegetation types using the simplified method described in Section 2.2.1, as well as to determine $\alpha_{\mathrm{p}} \bullet K_{\mathrm{b}}$ values at different phenological stages. Meteorological data are used to calculate the daily $\mathrm{ET}_{0}$ values.

One of critical difficulties faced in the regional application of this model is the discernment of vegetation (species) types and the inverse of their $\mathrm{LAI}_{\mathrm{m}}$ values at the catchment scale using remote sensing data. Fortunately, because there are few species types and the vegetation structure of desert riparian forests is relatively simple, vegetation types and their spatial distribution can be discerned from remote sensing data using the simple artificial supervised classification method. Furthermore, an empirical LAI inversion model is enough to obtain the LAI values from simple desert riparian forests.

The spatial calculation of $\mathrm{ET}_{\mathrm{m}}$ should be performed on each pixel; however, meteorological data are not usually available at the pixel scale. Consequently, upscaling the meteorological data is necessary to calculate spatial variations in $\mathrm{ET}_{\mathrm{m}}$. In the lower reach of the Tarim River, the land is flat and the climate is hyper-arid. The spatial variability of meteorological factors in this region is low. Hence, in this study we used the meteorological data observed by the Tieganlik weather station, which is located in the study area, to calculate the spatial $\mathrm{ET}_{\mathrm{m}}$.

\subsubsection{Remote Sensing Classification of Vegetation and their LAI Inversion}

Because the desert riparian forests in the study area can generally be classified into Populus woodlands and Tamarix thickets, the land cover types discerned by remote sensing data in the study area were divided into six categories: Populus woodland, Tamarix thicket, Phragmites grassland, farmland, water body and sandy land (bare soil). The water requirements of the Phragmites grassland, farmland and water body were not considered in the estimation of water requirements of desert riparian forests. Particularly, we ignored the water requirements of the Phragmites grassland in this area during our calculation of the VWR of desert riparian forests. The herbaceous vegetation here usually depends directly on the presence of river or rain water rather than groundwater, and it only survives beside the river channel or around the terminal lake. The growth of these herbaceous plants is controlled by surface or rain water, which differs from typical desert riparian species; therefor the water consumption characteristics of these plants do not satisfy the assumptions of our model. Given that the grassland is not important in maintaining the stability of desert riparian ecosystems in the lower Tarim River basin, and its area is relatively small, the water requirements of herbaceous vegetation were not included in the VWR of desert riparian forests.

Relevant Landsat 8 OLI remote sensing data from July 20th, 2013, which were downloaded from the website http://glovis.usgs.gov/, were used to classify the vegetation and identify the LAI inversion values in the study area. The pre-processing of the remote sensing data, including geometric and atmospheric corrections, was conducted prior to analysis.

A supervised classification method was used to classify the vegetation types based on the Landsat 8 OLI remote sensing data. A total of 1024 training samples were chosen from many field surveys across the lower reach of the Tarim River. The classification results are shown in Fig. 6a. Based on this result, the areas of Populus woodlands and Tamarix thickets in the lower reach of the Tarim River were approximately $3.364 \times 10^{4}$ ha and $4.053 \times 10^{4}$ ha, respectively. 
(a)

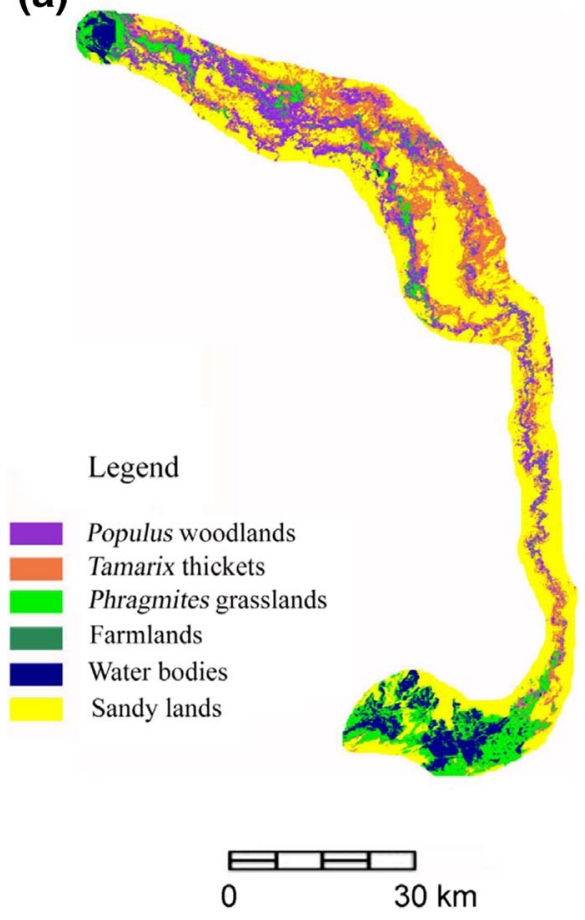

(b)

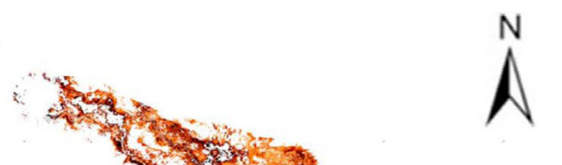

Fig. 6 Spatial distribution of the (a) vegetation categories and (b) leaf area index of the Tamarix thickets and the Populus woodlands in the lower basin of the Tarim River in China inverted by the Landsat 8 OLI remote sensed data

An empirical LAI inversion model was developed using the optimum vegetation index for Populus woodlands and Tamarix thickets in the study area. Detailed field measurements and an analysis are described in a previously published paper (Zhu et al. 2014). The LAI values of the Tamarix thickets were inverted based on the remotely sensed NDVI (Normalized Difference Vegetation Index). The empirical relationship $\left(R^{2}=0.69\right)$ between the LAI of the Tamarix thickets $\left(\mathrm{LAI}_{\mathrm{T}}\right)$ and the NDVI is:

$$
\mathrm{LAI}_{\mathrm{T}}=-0.216(\mathrm{NDVI})^{2}+5.744 \mathrm{NDVI}-0.356
$$

The LAI values of the Populus woodlands were inverted based on remotely sensed ARVI (Atmospherically Resistant Vegetation Index). The empirical relationship $\left(R^{2}=0.82\right)$ between the LAI of the Populus woodlands $\left(\mathrm{LAI}_{\mathrm{P}}\right)$ and the ARVI is:

$$
\mathrm{LAI}_{\mathrm{P}}=8.119(\mathrm{ARVI})^{2}+2.036 \mathrm{ARVI}+0.095
$$

Based on the empirical inversion models, the $\mathrm{LAI}_{\mathrm{m}}$ spatial distributions of the Populus woodlands and Tamarix thickets in the lower reach of the Tarim River were obtained from the Landsat 8 OLI data for July 20th, 2013 (Fig. 6b). The results showed the LAI $_{\mathrm{m}}$ values were generally low. The largest $\mathrm{LAI}_{\mathrm{m}}$ value for the Populus woodland was 1.85 , and that for the Tamarix thicket was 1.65. Mean $\mathrm{LAI}_{\mathrm{m}}$ values for both the Populus woodlands and the Tamarix thickets were 0.25 , indicating that the vegetation cover was very sparse in the study area, which is consistent with field observations (Chen et al. 2004). 


\subsection{Water Requirements under Current Vegetation Cover}

We estimated the VWR of the desert riparian forests in the lower reach of the Tarim River based on the remotely sensed spatial distributions of desert riparian vegetation and their LAI, meteorological data from the 2013 growing season, and fitted $\alpha_{\mathrm{p}} \bullet K_{\mathrm{b}}$ values (Table 1). The model is able to calculate daily VWR values, which provides more detailed temporal process information for desert riparian forest VWR vital to water resources management. The daily cumulative curve of total regional $\mathrm{ET}_{\mathrm{m}}$ shows seasonal variations in VWR (Fig. 7). The VWRs during the GP and LP were small, accounting for approximately $20 \%$ of total VWR during the growing season. During the MP, the slope of the cumulative curve did not vary, indicating that the mean daily VWR during the MP remained relatively stable at approximately $8.0 \times 10^{4} \mathrm{~m}^{3}$ per day during the 2013 growing season.

The model is also able to provide VWRs of different vegetation types. Table 2 identifies the VWRs for different phenological stages of the Populus woodlands and Tamarix thickets in the 2013 growing season. The data demonstrate the differences in VWRs for the two types of desert riparian forests in the study area, providing valuable information for desert and water resources management teams.

The spatial distribution of desert riparian forest VWRs throughout the study area is another important result of the model (Fig. 8a). Further analysis of this spatial distribution can reveal spatial patterns in VWRs (Fig. 9). During the 2013 growing season, the VWR for the largest area was only $76.5 \mathrm{~mm} \mathrm{~m}^{-2}$, while the area with a VWR of just under $400 \mathrm{~mm} \mathrm{~m}^{-2}$ comprised $97.4 \%$ of the total desert riparian forest area. Mean VWR in the 2013 growing season was only $134.6 \mathrm{~mm} \mathrm{~m}^{-2}$, reflecting the low water needs of desert riparian forests with sparse vegetation cover in hyper-arid regions.

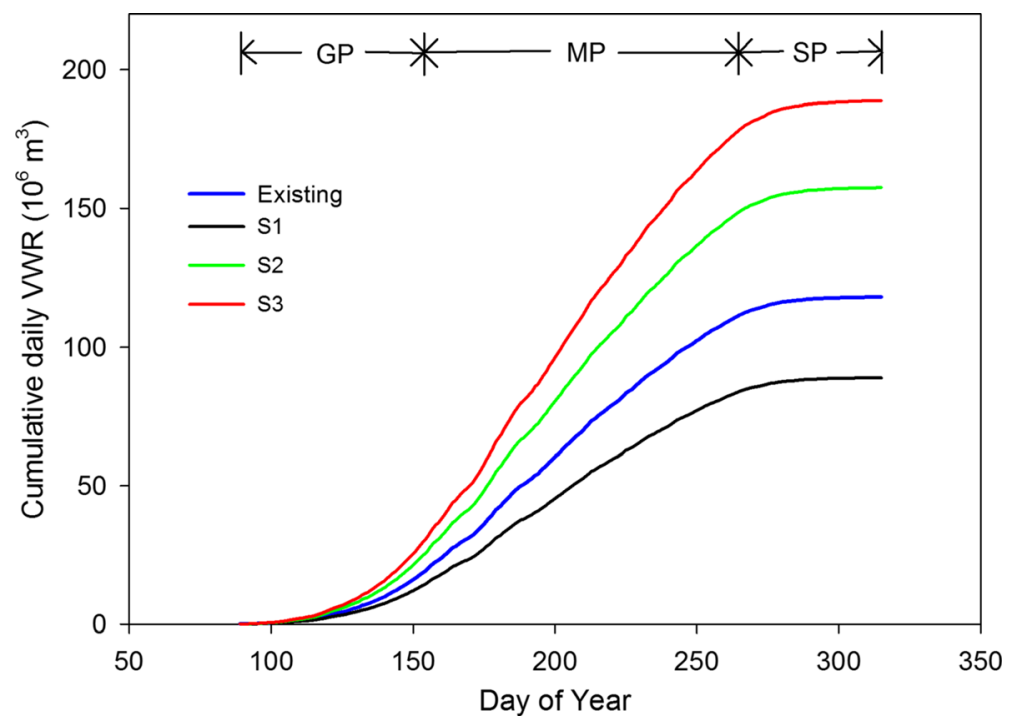

Fig. 7 Cumulative curve of total daily vegetation water requirements (VWR) of the desert riparian forests in the lower basin of the Tarim River in China under current vegetation cover condition (Existing) and for three different vegetation cover scenarios (S1, S2 and S3) 
Table 2 Vegetation water requirements (VWR) of two main desert riparian vegetation species at different phenological stages in the lower basin of the Tarim River, China

\begin{tabular}{|c|c|c|c|c|c|}
\hline \multirow{2}{*}{$\begin{array}{l}\text { Phenological } \\
\text { stages }\end{array}$} & \multicolumn{2}{|l|}{ Tamarix thickets } & \multicolumn{2}{|c|}{ Populus woodlands } & \multirow{2}{*}{$\begin{array}{l}\text { Total VWR } \\
\left(10^{6} \mathrm{~m}^{3}\right)\end{array}$} \\
\hline & $\operatorname{VWR}\left(10^{6} \mathrm{~m}^{3}\right)$ & Proportion (\%) & $\operatorname{VWR}\left(10^{6} \mathrm{~m}^{3}\right)$ & Proportion (\%) & \\
\hline GP & 5.197 & 4.4 & 14.230 & 12.0 & 19.427 \\
\hline MP & 41.313 & 35.0 & 50.282 & 42.6 & 91.595 \\
\hline SP & 3.483 & 2.9 & 3.643 & 3.1 & 7.126 \\
\hline Total VWR & 49.993 & 42.3 & 68.155 & 57.7 & 118.148 \\
\hline
\end{tabular}

\subsection{Water Requirements under Different Vegetation Cover Scenarios}

Because this model is both species-specific and spatially-explicit, setting different vegetation types and spatial patterns for the lower reaches of endorheic rivers allows the model to predict VWRs under different vegetation cover scenarios. Here, we set three scenarios of vegetation cover: scenario 1 (S1) represents deforestation, in which vegetated areas decreases by $2 \%$ and mean LAI decreases by $23 \%$ of existing vegetation cover; scenario 2 (S2) represents a single vegetation restoration scene, in which vegetated areas increase $26 \%$ while mean LAI increases $6 \%$ from the existing vegetation cover; and scenario 3 (S3) represents a second vegetation restoration scene, in which vegetated areas increase $42 \%$ while mean LAI increases by $13 \%$ of the existing vegetation cover (Table 3). The three scenarios were obtained using a simple algorithm. In this algorithm, we assumed that the desert riparian forest vegetation cover changes in the study area were related to the water supply rather than artificial control; thus, the spatial changes in the forests were primarily influenced by existing vegetation cover and the drought-tolerance of vegetation. According our field observations of riparian forests in hyper-arid regions, if the water conditions become worse at the decadal scale, the decrease in vegetation LAI is more obvious than the decrease in the distribution area of vegetation. However, if water conditions improve, the increase in the distribution area of vegetation is more obvious than that for vegetation LAI. Based on this reasoning, a simple algorithm was designed to obtain different $\mathrm{LAI}_{\mathrm{m}}$ values for each pixel. In the vegetation restoration scenarios, we assumed that when water conditions improved, vegetation cover with an LAI value greater than 0.7 changed little because the vegetation with an LAI value greater than 0.7 were usually not water-stressed, while the

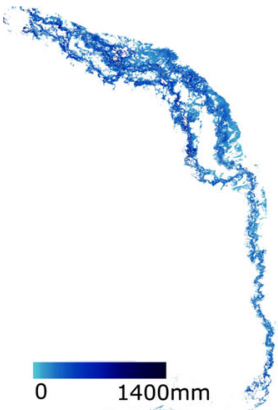

(a)

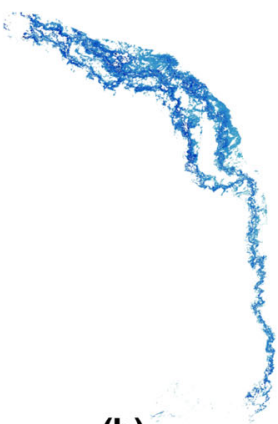

(b)

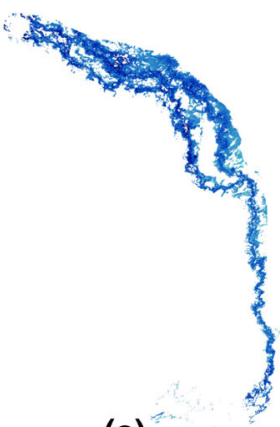

(c)

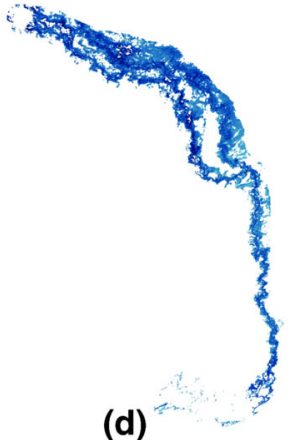

(d)

Fig. 8 Spatial distribution of vegetation water requirements in the lower basin of the Tarim River in China under different vegetation cover conditions: a current vegetation cover, b scenario 1, c scenario 2, and d scenario 3 


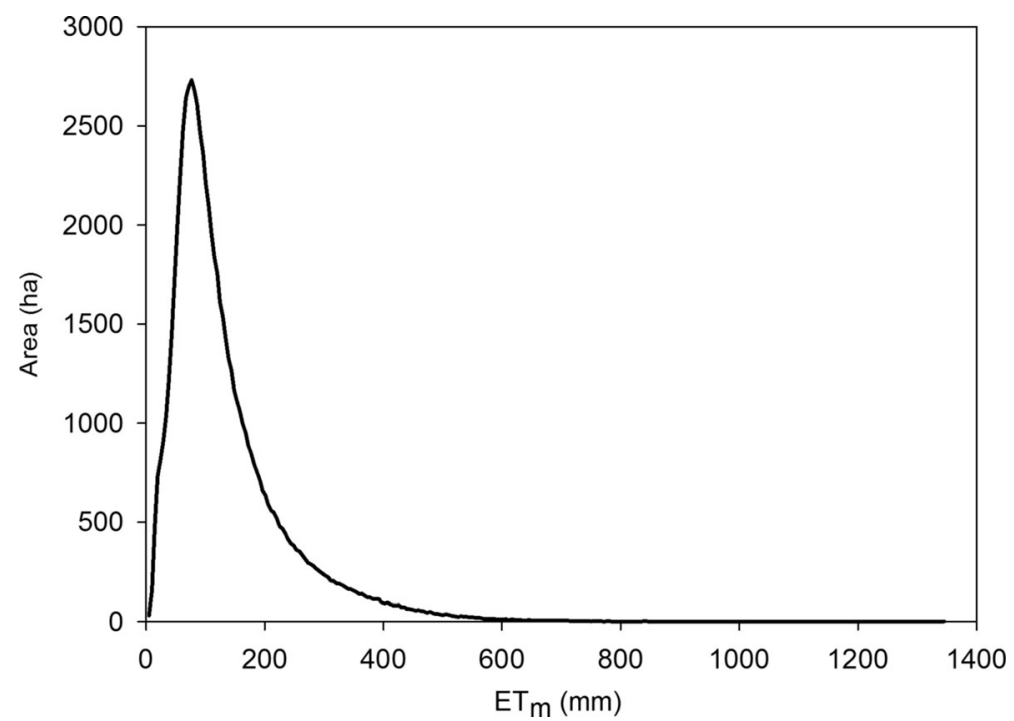

Fig. 9 Covering area of the different vegetation water requirements $\left(E T_{m}\right)$ in the lower basin of the Tarim River in China

vegetation with LAI value of less than 0.7 changed significantly because they were usually more sensitive to water conditions. However, in the deforestation process, when water conditions became worse, vegetation with LAI values greater than 0.7 were more sensitive to water conditions than those with values less than 0.7 .

Based on the 2013 weather data, we estimated the VWRs for desert riparian forests under the three vegetation cover scenarios (Table 3). The spatial distributions (Fig. 8b-d) and the temporal patterns (Fig. 7) of the VWRs under the three vegetation cover scenarios can also be displayed visually.

\section{Concluding Remarks}

The model presented here included an LAI variable in order to highlight the effect of the spatial variation of desert riparian vegetation cover on regional ET, making the model more

Table 3 Areas of vegetation cover, their mean LAI and the total vegetation water requirements (VWR) in the lower basin of the Tarim River under current vegetation cover condition and for three different vegetation cover scenarios

\begin{tabular}{lllc}
\hline Scenarios & Area of vegetation $\left(10^{3}\right.$ ha $)$ & Mean LAI & Total VWR $\left(10^{6} \mathrm{~m}^{3}\right)$ \\
\hline Existing & 74.2 & 0.25 & 118.148 \\
S1 & 72.7 & 0.19 & 88.822 \\
S2 & 93.2 & 0.27 & 157.542 \\
S3 & 105.4 & 0.29 & 188.831 \\
\hline
\end{tabular}


suitable in hyper-arid regions. Moreover, the model is species-specific, and can consequently be used to estimate the VWRs of different desert riparian vegetation species, assuming the appropriate $\alpha_{\mathrm{p}} \cdot K_{\mathrm{b}}$ values for different desert riparian vegetation species at different growth stages can be obtained. The test results indicated that the model provide a feasible estimate of the VWRs for desert riparian forests. Because the model used two dominant desert riparian species in arid northwestern China, Tamarix thicket and Populus woodland, the positive model test result also indicate that the model may be applied effectively in desert riparian ecosystems along other endorheic rivers in arid northwestern China.

The model also exhibited its practical applications for water resources management of rivers in arid regions. First, this model is simple, easy to operate, and only requires a few input data items and parameters. When the $\alpha_{\mathrm{p}} \cdot K_{\mathrm{b}}$ values have been obtained, and the algorithms to discern vegetation categories and the inverse of the LAI values from remotely sensed data have been established, running the model in a single region only requires meteorological data. Second, this model not only provides continuous historical, near real-time and forecasted VWR estimations of desert riparian forests based on historical, real-time observational and forecasted meteorological data, but also shows the spatial patterns of VWRs in certain areas based on the remote sensing data. Estimates of temporal fluctuations and spatial distributions of VWRs can provide more abundant information to improve the efficiency of water use. Third, this model can predict VWRs under different vegetation spatial distributions and covers, which can provide a valuable reference point for how to balance the conflict between ecological restoration and water use, thus informing the sustainable management of water resources and desert riparian ecosystems in arid regions.

Nevertheless, this model has its limitations. The VWR in this model was defined as the regional ET under non-water-stressed conditions. However, this definition does not consider the impacts of other environmental factors such as salinization, desertification, etc., on desert riparian ecosystem health and functionality, which would directly affect the VWR. Additionally, this model estimates VWR rather than EWR and, thus, cannot provide immediate guidance on water resources allocation. Nevertheless, this model can serve as a foundation for determining EWR along rivers in arid regions.

Briefly, the model to estimate the water requirements of desert riparian forests in arid regions presented here is novel because the model is spatially explicit and highlights the effect of vegetation cover's spatial variability on surface ET amount in arid regions, and is also species specific, reflecting the different water needs of different desert riparian plants. The model is also feasible for desert riparian ecosystems in hyper-arid regions and has practical application for water resources management because it is easy to operate and can provide abundant information related to the spatiotemporal patterns of vegetation water requirements under different vegetation cover scenarios. This model can serve as a useful tool for water resources management agencies to improve their decisions related to river water allocation between irrigation farming and natural ecosystems in arid regions.

Acknowledgments This study was funded by the National Natural Science Foundation of China (Grant No. 41271050 and Grant No. 41390463). The authors thank Prof. Yi Luo and Dr. Ping Wang for their valuable discussions over the course of this study. We also thank Dr. Pei Zhang for her help in data processing and field observations. 


\section{References}

Abdurahman M, Kurban A, Ablat A (2008) Study on phenological characters of populus euphratica Oliv. in the lower reaches of the Tarim River Arid Zone Research (in Chinese) 25:525-530

Acreman M et al. (2014) Environmental flows for natural, hybrid, and novel riverine ecosystems in a changing world. Front Ecol Environ 12:466-473. doi:10.1890/130134

Allen RG, Pereira LS, Reas D, Smith M (1998) Guidelines for computing crop water requirements. FAO Irrigation and Drainage Paper No. 56. United Nations, FAO, Roma, Italy

Bai Y (1998) Studies on phenological patterns of the main shrubs in Yanchi sandy land. J Arid Land Resources Environ (in chinese) 12:82-86

Bertrand G, Goldscheider N, Gobat JM, Hunkeler D (2012) Review: From multi-scale conceptualization to a classification system for inland groundwater-dependent ecosystems. Hydrogeol J 20:5-25. doi:10.1007/ s10040-011-0791-5

Chen YN (2003) Impact of human activities on water resources and ecological problems in Tarim River basin, China J Exp Bot 54:61-61

Chen YN et al. (2004) Analysis on the ecological benefits of the stream water conveyance to the dried-up river of the lower reaches of Tarim River. China Sci China Ser D 47:1053-1064. doi:10.1360/03yd0101

Daly E, Porporato A, Rodriguez-Iturbe I (2004) Coupled dynamics of photosynthesis, transpiration, and soil water balance. Parst I: Upscaling from Hourly to Daily Level J Hydrometeorol 5:546-558. doi:10.1175/ 1525-7541(2004)005<0546:CDOPTA $>2.0 . \mathrm{CO} ; 2$

Feng Q, Cheng GD (1998) Current situation, problems and rational utilization of water resources in arid northwestern China. J Arid Environ 40:373-382

Feng Q, Liu W, Si JH, Su YH, Zhang YW, Cang ZQ, Xi HY (2005) Environmental effects of water resource development and use in the Tarim River basin of northwestern China. Environ Geol 48:202-210. doi:10. 1007/s00254-005-1288-0

Fernandes R, Korolevych V, Wang S (2007) Trends in Land Evapotranspiration over Canada for the Period 1960-2000 Based on In Situ Climate Observations and a Land Surface Model. J Hydrometeorol 8:10161030. doi:10.1175/JHM619.1

Foley JA, Prentice IC, Ramankutty N, Levis S, Pollard D, Sitch S, Haxeltine A (1996) An integrated biosphere model of land surface processes, terrestrial carbon balance, and vegetation dynamics. Global Biogeochem Cy 10:603-628. doi:10.1029/96gb02692

Gleick PH (1998) Water in crisis: paths to sustainable water use. Ecol Appl 8:571-579. doi:10.2307/2641249

Hu B, Cui BS, Dong SK, Zhai HJ, Liu ZY (2009) Ecological Water Requirement (EWR) Analysis of High Mountain and Steep Gorge (HMSG) River-Application to Upper Lancang-Mekong River. Water Resour Manag 23:341-366. doi:10.1007/s11269-008-9278-0

Irmak S, Kabenge I, Rudnick D, Knezevic S, Woodward D, Moravek M (2013) Evapotranspiration crop coefficients for mixed riparian plant community and transpiration crop coefficients for common reed, Cottonwood and Peach-leaf Willow in the Platte River Basin, Nebraska-USA. J Hydrol 481:177-190. doi:10.1016/j.jhydrol.2012.12.032

Izadifar Z, Elshorbagy A (2010) Prediction of hourly actual evapotranspiration using neural networks, genetic programming, and statistical models. Hydrol Process 24:3413-3425

Li WH, Zhou HH, Fu AH, Chen YP (2013) Ecological response and hydrological mechanism of desert riparian forest in inland river, northwest of China. Ecohydrology 6:949-955. doi:10.1002/Eco.1385

Ling HB, Guo B, Xu HL, Fu JY (2014) Configuration of water resources for a typical river basin in an arid region of China based on the ecological water requirements (EWRs) of desert riparian vegetation. Glob Planet Chang 122:292-304. doi:10.1016/j.gloplacha.2014.09.008

Liu B, Zhao WZ, Chang XX, Li SB, Zhang ZH, Du MW (2010) Water requirements and stability of oasis ecosystem in arid region. China Environ Earth Sci 59:1235-1244. doi:10.1007/s12665-0090112-7

Meijer KS, van der Krogt WNM, van Beek E (2012) A New Approach to Incorporating Environmental Flow Requirements in Water Allocation Modeling. Water Resour Manag 26:1271-1286. doi:10.1007/s11269-0119958-Z

Merritt DM, Bateman HL (2012) Linking stream flow and groundwater to avian habitat in a desert riparian system. Ecol Appl 22:1973-1988. doi:10.1890/12-0303.1

Orellana F, Verma P, Loheide SP, Daly E (2012) Monitoring and Modeling Water-Vegetation Interactions in Groundwater-Dependent Ecosystems. Rev Geophys 50:RG3003. doi:10.1029/2011rg000383

Rumbaur C et al. (2015) Sustainable management of river oases along the Tarim River (SuMaRiO) in Northwest China under conditions of climate change earth system. Dynamics 6:83-107. doi:10.5194/esd-6-83-2015

Sellers PJ et al. (1997) Modeling the exchanges of energy. Water, and Carbon Between Continents and the Atmosphere Science 275:502-509. doi:10.1126/science.275.5299.502 
Spano D, Snyder RL, Sirca C, Duce P (2009) ECOWAT - A model for ecosystem evapotranspiration estimation. Agric For Meteorol 149:1584-1596. doi:10.1016/j.agrformet.2009.04.011

Sumner DM, Jacobs JM (2005) Utility of penman-Monteith, Priestley-Taylor, reference evapotranspiration, and pan evaporation methods to estimate pasture evapotranspiration. J Hydrol 308:81-104. doi:10.1016/j. jhydrol.2004.10.023

Tao H, Gemmer M, Song YD, Jiang T (2008) Ecohydrological responses on water diversion in the lower reaches of the Tarim River. China Water Resour Res 44:W08422. doi:10.1029/2007wr006186

Wang S (2008) Simulation of Evapotranspiration and Its Response to Plant Water and CO2 Transfer Dynamics. J Hydrometeorol 9:426-443. doi:10.1175/2007JHM918.1

Wang K, Dickinson RE (2012) A review of global terrestrial evapotranspiration: observation, modeling, climatology, and climatic variability. Rev Geophys 50:RG2005. doi:10.1029/2011 rg000373

Wang L, D'Odorico P, Evans JP, Eldridge DJ, McCabe MF, Caylor KK, King EG (2012) Dryland ecohydrology and climate change: critical issues and technical advances. Hydrol Earth Syst Sc 16:2585-2603. doi:10. 5194/hess-16-2585-2012

Xu HL, Ye M, Song YD, Chen YN (2007) The natural vegetation responses to the groundwater change resulting from ecological water conveyances to the lower tarim river. Environ Monit Assess 131:37-48. doi:10.1007/ s10661-006-9455-7

Ye ZX, Chen YN, Li WH (2010) Ecological water demand of natural vegetation in the lower Tarim River. J Geogr Sci 20:261-272. doi:10.1007/s11442-010-0261-3

Yuan G, Zhang P, Shao M-a, Luo Y, Zhu X (2014) Energy and water exchanges over a riparian Tamarix spp. stand in the lower Tarim River basin under a hyper-arid climate. Agric For Meteorol 194:144-154. doi:10. 1016/j.agrformet.2014.04.004

Yuan G, Luo Y, Shao M, Zhang P, Zhu X (2015) Evapotranspiration and its main controlling mechanism over the desert riparian forests in the lower Tarim River Basin. Sci China Earth Sci 58:1032-1042. doi:10.1007/ s11430-014-5045-7

Zhang YC, Yu JJ, Wang P, Fu GB (2011) Vegetation responses to integrated water management in the Ejina basin, northwest China. Hydrol Process 25:3448-3461. doi:10.1002/Hyp.8073

Zhao WZ, Chang XL, He ZB, Zhang ZH (2007) Study on vegetation ecological water requirement in Ejina Oasis. Sci China Ser D 50:121-129. doi:10.1007/s11430-007-2035-Z

Zheng D, Yin Y (2010) Eco-reconstruction in Northwest China. In: Courel M-F (ed) Schneier-Madanes G. Water and Sustainability in Arid Regions, Springer Netherlands, pp. 3-14. doi:10.1007/978-90-481-2776-4_1

Zhu J, Yu J, Wang P, Zhang Y, Yu Q (2012) Interpreting the groundwater attributes influencing the distribution patterns of groundwater-dependent vegetation in northwestern China. Ecohydrology 5:628-636. doi:10. $1002 /$ eco. 249

Zhu X, Yuan G, Yi X, Du T (2014) Leaf area index inversion of riparian forest in the lower basin of Tarim River based on Landsat 8 OLI images. Arid Land Geography (in Chinese) 37:1248-1256 